\title{
Estimating Probabilistic Cost and Time Contingency for Residential Building Projects
}

\author{
Rafiq M. Choudhry ${ }^{1}$, Sana Rafiq ${ }^{2}$, Anwar Ahmed ${ }^{2}$, Tauqir Ahmed ${ }^{1}$ \\ ${ }^{1}$ Department of Civil Engineering, College of Engineering, Al Imam Mohammad Ibn Saud Islamic University (IMSIU) \\ Riyadh, Kingdom of Saudi Arabia \\ rchoudhry@imamu.edu.sa; tamalik@imamu.edu.sa \\ ${ }^{2}$ School of Civil and Environmental Engineering, National University of Sciences and Technology \\ Islamabad, Pakistan \\ sana.rafiq46@gmail.com; dranwaar@scee.nust.edu.pk
}

\begin{abstract}
Many risks are associated with construction industry because of its highly diversified nature. Contingency reserves are designed and added to the project's estimate to cater for these risks. Different techniques are used worldwide to calculate contingency but unfortunately, Pakistan's construction industry continues to use the 'traditional percentage methodology'. In this technique, a preset amount, usually 5\% - 10\% of the project's cost is added to the base cost estimate without identifying and analysing the risks. Time contingency is over looked in majority of the projects and if considered, it is based on subjective opinion of experts. This predetermined amount of uncertainty denotes the arbitrariness and becomes a reason for cost and time overrun in majority of projects in the country. This research aims to develop a framework that can circumvent this uncertainty by using probabilistic quantitative risk techniques. It proposes a probabilistic model for predicting total cost and duration of the project by translating the effect of risks. Rational contingency reserves for cost and time are predicted using the model by determining risk contingency factors.
\end{abstract}

Keywords: Construction Projects, Cost Contingency, Time Contingency, Probabilistic Cost.

\section{Introduction}

During planning phase of any construction project, project managers find it extremely challenging to reliably forecast project's duration and budget at completion for the uniqueness and uncertainty intrinsic to project activities [1], [2]. Effective risk management can help project managers' control and handle uncertainties in a project [3]. It uses contingency as a tool to abate the consequence of risks on project's objective [4].

Many authors have worked on the techniques to calculate most probable project's estimate. Spooner [5] is considered amongst the pioneer who developed probabilistic project's estimate. Ibbs and Crandall [6] used multi attributed objective function to create a statistical decision making model for risk analysis. Yeo [7] presented an approach of two-tiered contingency allocation for determining probable cost of the project; however, Ranasinghe [8] modified it by allocating the uncertainties to discrete bill item costs. Ballard and Howell [9] worked on assigning a buffer to the project schedule depending on the uncertainty involved. Hassanein and Cherlopalle [10] forecasted the probabilistic project's cost estimate by addressing the uncertainties using fuzzy theory, whereas Jin and Zhang [11] used Artificial Neural Network (ANN). Mak and Picken [12] forecasted project's contingency for Hong Kong government by identifying, analysing and quantifying project cost risks, on the other hand Hastak and Shaked [13] created a risk evaluation model for international construction projects by using 73 risks factors. Reliability criteria is another technique used for calculating probable duration which states placing contingency with the succeeding activity to keep the activity reliable depending on the risks associated with it [14],

In recent studies, a quantitative model is developed that uses identified risk events or factors to forecast the contingency required for a project [15]-[17]. Touran [18] recommends the use of probabilistic approach to develop a probable estimate; Barraza and Bueno [19] recommend Monte Carlo Simulation, however, Sonmez et al. [15] preferred linear regression analysis. Touran [20] emphasized that schedule should be elastic enough to cope with the time risks without negatively affecting the total project duration. Because the schedule variability is dependent on the behaviour of 
the activities, time contingency should be estimated by taking into account the uncertainty of respective activity instead of basing on human judgment [21], [22].

Despite various attempts to calculate contingency, overruns remain a perpetual problem in the delivery of projects [23]. Construction industry specifically of Pakistan continues to suffer from cost and time overrun due to its failure to adopt risk management practices. Mostly managers evade the systematic approach of identifying, analysing, and quantifying the risks, using proper statistical knowledge through a subjective approach of adding $10-15 \%$ to the base cost estimate for contingency [24]. Situation is more alarming in case of time contingency as no valuable consideration is given to this aspect by the construction industry in the country. This results in overruns for projects [25].

The main aim of this study is to develop a probabilistic framework by risk management processes, to estimate cost and time contingency, using data from housing construction projects in Pakistan. This framework is to contribute to the current practices of project estimation in planning phase. It can help considering the uncertainty, instead of relying on human judgement, without any technical or statistical knowledge and with least effort.

\section{Research Method}

To estimate cost and time contingency, this study uses a comprehensive framework for which traditional and probabilistic cost and time estimation models are developed. Traditional model observes the common practice in the industry for estimation while probabilistic model development is segmented into different phases as per the risk management processes. Primarily, planning is done to define projects and approach taken to identify and evaluate the project risks. Secondly, risks are identified that have their effect on project's objectives. Thirdly, potential consequences of the identified risks are evaluated. Lastly, risk response strategy is designed to help alleviate the effects of identified risks. Comparison of traditional estimate and probabilistic estimate, incorporated with the effect of risks involved, can help in developing cost and time contingency factors, which are required with the base estimate to get most probable estimate.

Housing construction projects are selected for this study due to their simplicity and wide applicability in the construction industry. A total 144 houses are selected in different parts of Rawalpindi and Islamabad in the country. The authors contacted and visited the owners and/or contractors of these 144 projects to conduct interviews and collect data, which include detail design drawings, finishes, total cost and duration, and any uncertain event that occurred during the execution phase.

\subsection{Development and Validation of Traditional Cost and Time Estimation Model}

Estimates of each of the 144 selected projects are determined by developing a simple Excel based model. Traditional schedule is developed by sequencing the activities of construction of a house and total duration is determined individually using CPM. Cost estimate of each project is developed by collaborating quantities from the quantity take-off sheet, developed for each project from detailed drawings, and rates from the rate analysis sheets. Rates are based on the past eleven years' item rates data obtained from the Punjab Finance Department's official website.

Project performance is measured by comparing these estimates with the actual cost and duration of the project, using earned value management (EVM) technique by calculating schedule performance index (SPI) and cost performance index (CPI). The graphical representation of SPI for 144 projects is shown in Figure 1(a) and that of CPI in Figure 1(b). These confide that $85 \%$ of the projects have SPI less than 0.80; whereas the same number of percentage of projects have CPI less than 0.90 . This indicates that more than $85 \%$ of projects have cost overrun of minimum $10 \%$ of the final cost and are $20 \%$ behind the schedule. To cope with this, contingency is introduced to the project's estimate by identifying the risks involved in the project and calculating their effect. 


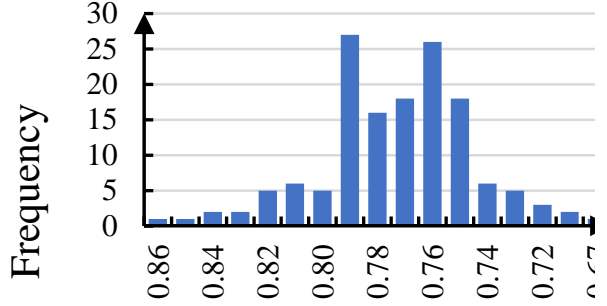

SPI

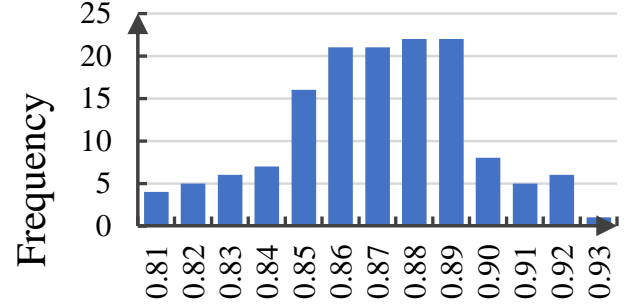

CPI

(a) Schedule performance index (SPI)

(b) Cost performance index(CPI)

Fig. 1: Performance indices.

\subsection{Cost and Time Risks Factors}

Through interviews of construction professionals, using AHP technique, five (5) risk categories are identified that have significant impact on cost and schedule of housing projects. This research is focused on project's risks in the execution phase, assuming an ideal case for all other scenarios. The identified risk categories are (1) machine efficiencies, (2) labour efficiencies, (3) material wastages, (4) construction items' rate and (5) duration of activities.

Cost of equipment is 10 to $30 \%$ of total cost of the project and if not properly managed, it can increase the project's cost considerably [26]. Similarly, labour cost about 30-35\% of total project's cost and loss of labour productivity increases the cost up to $9-14 \%$ [27]. Subjective opinions from over 80 professionals are taken to determine machine and labour efficiency in the construction industry of Pakistan by questionnaire survey. Effective and comprehensive responses are gathered and using @RISK as the simulation tool, best distribution is fitted over the collected responses to get probabilistic mean and standard deviation of the efficiency of machine and labour force involved in the project.

During project execution, materials' wastage rate is generally higher than planned, which results into increased cost. Expert opinion approach is used to determine the wastage rate for construction materials. Twenty-five (25) experts are interviewed and triangular distribution in @ RISK is fitted over the responses to determine the most probable wastage rate.

The experts regard fluctuation in construction items' rates as the major reason for cost overrun during the risks identification interviews. Pakistan Engineering Council (PEC) price adjustment formula is available, but only applicable for projects with over one-year duration. Since most of the housing projects have duration less than a year, therefore this formula is not used. To cater for this risk, effect of time on construction items is studied for which prices are collected from the Punjab Finance Department for past eleven years. Construction price index (CPIn) is established for individual item on quarterly basis, by selecting a base item price. If, across two times tb (time of the base price) and ti (time for which CPIn is determined), the same quantity of goods or services are sold, but under different prices, then CPIn is given as equation (1) [28].

$$
\mathrm{CPI}=\frac{P_{x} t_{i} \cdot Q_{x} t_{i}}{P_{x} t_{b} \cdot Q_{x} t_{b}}
$$

Where, Pxt denotes the price of $\mathrm{x}$ in period t, Qxt denotes the quantity of $\mathrm{x}$ sold in period t. CPIn is calculated for past 11 years to determine the future cost scenarios of the project.

Duration of 39 different activities of the housing projects is determined by interviewing twenty-seven (27) professionals. PERT distribution in @RISK is fitted over the responses collected and probabilistic mean and standard deviation are calculated.

\subsection{Development of Probabilistic Cost and Time Estimation Model}

Probabilistic schedule is prepared by sequencing the activities contingent to dependency and relationship with the preceding activities. By simulating the project, using Monte Carlo Simulation technique in @ RISK, probable project duration (PPD) is evaluated (Eq. 2). 


$$
P P D=\sum_{i=1}^{n} P D_{i}
$$

Where, $\mathrm{PDi}=$ Simulated probable duration of activities lying on critical path. Simulated probable duration (PDi) is a function of duration (Di) of that activity with 'PERT' distribution and efficiency of labours and machines with probability distributions used in that activity.

Total project cost (TPC) is predicted by summing the simulated probabilistic cost of each activity in the project (ACa) (see Eq. 3).

$$
T P C=\sum_{a=1}^{z} A C_{a}
$$

Where, $\mathrm{ACa}=$ Cost of all activities in the project.

Cost of each activity depends on the probabilistic rate, which is calculated by multiplying the quantities (labour, material, and machinery) used with rate, growth factor, and efficiency in case of material \& labour, and wastages in case of material. Growth factor is predicted by extrapolating the CPI values to measure the inflation individually for all items.

\section{Results and Analysis}

The developed probabilistic model allows analysis of a wider continuum of data by using Monte Carlo Simulation and @RISK as the simulation tool. Using 4,000 iterations, simulations are run over uncertainties of the identified risks categories in the model and probabilistic estimates were developed for every project. SPI and CPI of all the projects is calculated, graphical representation of which is shown in Figure 2(a) and 2(b). The graph indicates that SPI of $80 \%$ of the projects is more than 0.97 , which suggests an error of less than $\pm 3.0 \%$. Similarly, CPI of $70 \%$ of the projects is greater than 0.96 , which indicates an error of less than $4 \%$ in the calculated total cost.

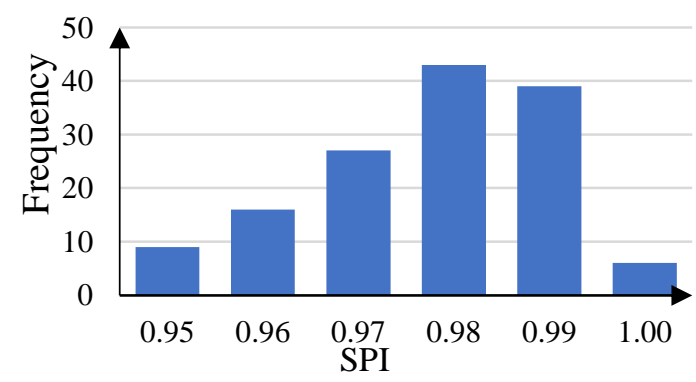

(a) Schedule performance index (SPI)

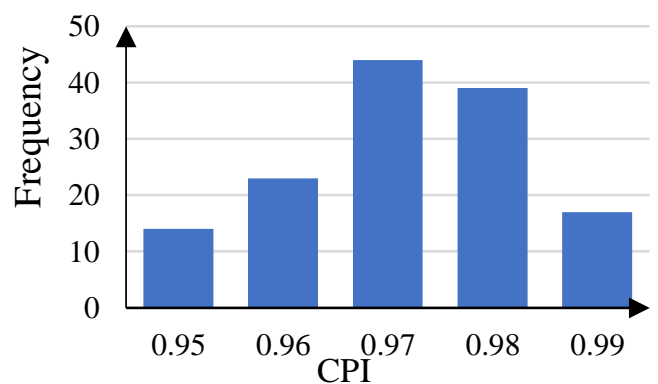

(b) Cost performance index(CPI)

Fig. 2: Performance indices.

Comparison of traditional and probabilistic project cost estimates determines cost contingency factors that is the required contingency to cope with risks involved. Cost contingency factors are estimated for different time lags between planning and year of actual construction. By best fitting the values obtained for cost contingency factors, cost contingency graphs for three different house sizes are developed for time lag from zero to 5 years (see Figure 3). The graphs show that as the time lag between planning and the actual execution increases, the cost contingency increases. It also reveals that cost contingency is directly proportional to the size of the project. 


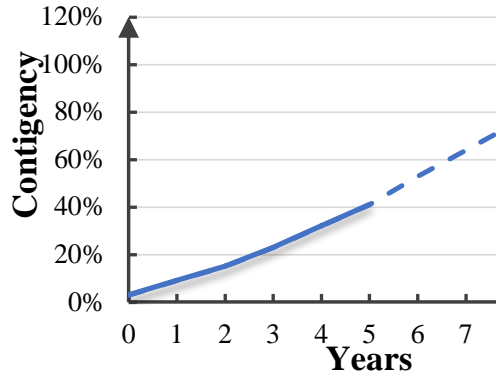

(a) House of $1125 \mathrm{sft}$

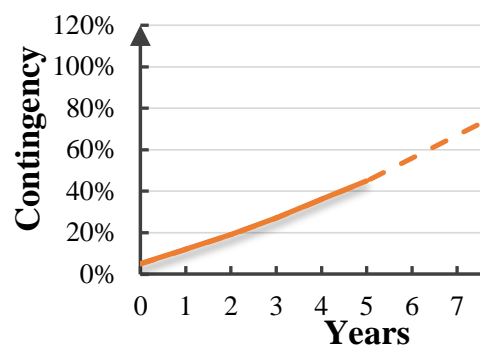

(b) House of $2500 \mathrm{sft}$

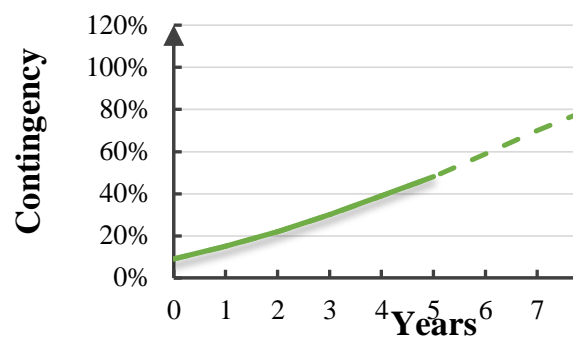

(c) House of $4500 \mathrm{sft}$

Fig. 3: Cost contingency for different size housing projects.

Time contingency factor is obtained by calculating the difference between the duration predicted traditionally and probabilistically. For determining probabilistic time contingency with respect to the covered area of a project, the factor is plotted on a graph with contingency in days on $\mathrm{y}$-axis and covered area of the building on $\mathrm{x}$-axis. By best fitting a line on factors of 144 projects, a time contingency graph is developed for determining the time contingency with respect to the covered area (see Figure 4).

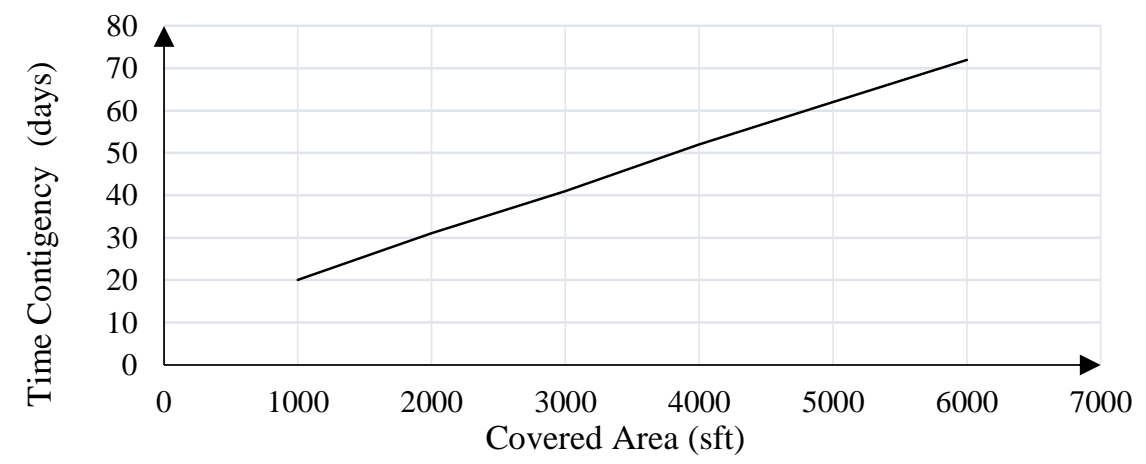

Fig. 4: Time contingency.

\section{Discussion}

This research focuses on improvement of contingency calculation techniques for housing projects. Many field experts prefer to use deterministic or traditional technique for contingency calculation that involves usage of a single crisp value, because of its simplicity and ease in application [29]. This research shows the flaws of this approach which are consistent with the views of various researches [12], [29], [30].

Several authors have already proposed a range of other probabilistic approaches for contingency calculation, which include decision tree analysis [31], [32] and fault tree analysis [33], [34]. Various researchers [35], [36] have adopted probabilistic approach using "failure mode and effect analysis" and "system dynamics". Furthermore, a number of authors advocate that a contingency model, that uses a fuzzy arithmetic technique for determining contingency, provide accurate results [30], [37]. In the past, numerous ways to conclude cost contingency have also been introduced, such as Artificial Neural Network [11], [38], Belief Network [39], [40] and linear regression [2], [15], [41].

Majority of these researches reckons statistical and scientific understanding from the user, whereas many construction personnel do not have any arithmetical knowledge, thus becoming a major restraint. This study has presented a contingency value, instead of suggesting a technique for calculation, to be added to the estimated value by looking through the graphs (Fig. $3 \& 4$ ). This research thus becomes the first of its kind giving probabilistic contingency values with the same ease of the subjective approach, but with much greater accuracy.

It is, however, valuable to consider these points: 1) Many known and unknown parameters affect the project's objective. This work considers top ranked project's risks in the execution phase; 2) The results are for residential projects but the probable technique of this study and its results can be tracked for further research. 


\section{Concluding Remarks}

This research develops a simulated probabilistic estimate by identifying the risks involved and translating their effect on the project's estimate. The paper illustrates by calculating CPI and SPI (Fig. 1 and Fig. 2) that estimates developed probabilistically offer more precise outcome as compared to the traditional estimates. Probabilistic cost contingency obtained demonstrates that contingency varies with the project type, size, and duration (see Fig. 3). As the size and duration of the project changes, the contingency associated with it, also changes. Probable time contingency helps in providing a more probable timeline of the project, which also escalates with the increase in the size of the project. The findings of this research can help construction professionals in making informed decisions in the planning phase. The graphs put forth for calculating contingency can assist construction professionals, who have little statistical knowledge for accurately predicting well-informed and precise project estimate. The graphs developed have eased the path to certainty of the project.

\section{References}

[1] D. N. Ford, “Achieving Multiple Project Objectives through Contingency Management," J. Constr. Eng. Manag., vol. 128, no. 1, pp. 30-39, 2002.

[2] A. E. Thal Jr., J. J. Cook, and E. D. White III, "Estimation of Cost Contingency for Air Force Construction Projects," J. Constr. Eng. Manag., vol. 136, no. 11, pp. 1181-1188, 2010.

[3] E. Kutsch And M. Hall, "Deliberate ignorance in project risk management," Int. J. Proj. Manag., vol. 28, no. 3, pp. 245-255, 2010.

[4] Project Management Institute, A Guide to the Project Management Body of Knowledge, 5th ed. Newtown Square, PA, 2013.

[5] J. E. Spooner, "Probabilistic estimating," J. Constr. Div., vol. 100, no. 1, pp. 65-77, 1974.

[6] C. W. Ibbs and K. C. Crandall, "Construction risk: Multi-attribute approach," J. Constr. Eng. Manag., vol. 108, no. 2, pp. 187-200, 1982.

[7] K. Yeo, "Risks, classification of estimates, and contingency management," J. Manag. Eng., vol. 6, no. 4, pp. 458470, 1990.

[8] M. Ranasinghe, "Contingency allocation and management for building projects," Constr. Manag. Econ., vol. 12, no. 3, pp. 233-243, 1994.

[9] G. Ballard and G. Howell, "Toward construction JIT," in 11th Annual ARCOM Conference, 1995.

[10] A. A. B. Hassanein and V. Cherlopalle, "Fuzzy sets theory and range estimating," AACE International Transactions, K4111. Hassanein, 1999.pdf," AACE Int. Trans., vol. K4, no. 1, 1999.

[11] X. H. Jin and G. Zhang, "Modelling optimal risk allocation in PPP projects using artificial neural networks," Int. J. Proj. Manag., vol. 29, no. 5, pp. 591-603, 2011.

[12] S. Mak and D. Picken, "Using Risk Analysis to Determine Construction Project Contingencies," J. Constr. Eng. Manag., vol. 126, no. 2, pp. 130-136, 2000.

[13] M. Hastak and A. Shaked, "ICRAM-1: Model For International Construction Risk Assessment," J. Manag. Eng., vol. 16, no. 1, pp. 59-69, 2000.

[14] M. Park and F. Peña-mora, "Reliability Buffering for Construction Projects," J. Constr. Eng. Manag., vol. 130, no. 5, pp. 626-637, 2004.

[15] R. Sonmez, A. Ergin, and M. T. Birgonul, "Quantitative Methodology for Determination of Cost," J. Constr. Eng. Manag., vol. 23, no. 1, pp. 35-39, 2007.

[16] D. F. Cioffi and H. Khamooshi, "A practical method of determining project risk contingency budgets," J. Oper. Res. Soc., vol. 60, no. 4, pp. 565-571, 2009.

[17] D. Mohamed, F. Srour, W. Tabra, and T. Zayed, "A Prediction Model For Construction Project Time Contingency," in Construction Research Congress 2009, pp. 736-745, 2009.

[18] A. Touran, "Probabilistic model for cost contingency," J. Constr. Eng. Manag., vol. 129, no. 3, pp. 280-284, 2003.

[19] G. A. Barraza and R. A. Bueno, "Cost Contingency Management," JJournal Manag. Eng., vol. 23, no. 3, pp. 140146, 2007.

[20] A. Touran, "Calculation of Contingency in Construction Projects," Trans. Eng. Manag., vol. 50, no. 2, pp. 135-140, 2003. 
[21] B. Pollack-Johnson and M. J. Liberatore, "Project planning under uncertainty using scenario analysis," Proj. Manag. J., vol. 36, no. 1, pp. 15-26, 2005.

[22] G. A. Barraza, "Probabilistic Estimation and Allocation of Project Time Contingency," J. Constr. En- gineering Manag., vol. 137, no. 4, pp. 259-265, 2011.

[23] P. E. D. Love, X. Wang, C. Sing, and R. L. K. Tiong, "Determining the Probability of Project Cost Overruns," J. Constr. Eng. Manag., vol. 139, no. 3, pp. 321-330, 2013.

[24] R. Burger, "Contingency, quantifying the uncertainty," Cost Eng., vol. 45, no. 8, pp. 12-17, 2003.

[25] PEC Islamabad, "Standard Procedure for Evaluation of Proposals for Procurement of Engineering Services," Islamabad, 2009.

[26] S. C. Sharma, Construction Equipment and Management. Mumbai: Khanna Publishers, 1998.

[27] E. M. Rojas, Construction Productivity: A Practical Guide for Building and Electrical Contractors. Fort Lauderdale, USA: J. Ross Publishing, 2008.

[28] A. Deaton and S. Zaidi, "Guidelines for Constructing Consumption Aggregates for Welfare Analysis.," Washington, United States, 2002.

[29] A. Idrus, M. F. Nuruddin, and M. A. Rohman, "Development of project cost contingency estimation model using risk analysis and fuzzy expert system,” Expert Syst. Appl., vol. 38, no. 3, pp. 1501-1508, 2011.

[30] M. M. Elbarkouky, A. R. Fayek, N. B. Siraj, and N. Sadeghi, "Fuzzy arithmetic risk analysis approach to determine construction project contingency," J. Constr. Eng. Manag., vol. 142, no. 12, 2016.

[31] P. K. Dey, "Project risk management: A combined analytic hierarchy process and decision tree approach," Cost Eng., vol. 44, no. 3, pp. 13-27, 2002.

[32] A. Ahmed and S. Kayis, B. Amornsawadwatana, "A review of techniques for risk management in projects," Benchmarking An Int. J., vol. 14, no. 1, pp. 22-36, 2007.

[33] C. T. Lin and M. J. J. Wang, "Hybrid fault tree analysis using fuzzy sets," Reliab. Eng. Syst. Saf., vol. 58, no. 3, pp. 205-213, 1997.

[34] M. Abdelgawad and A. R. Fayek, "Fuzzy reliability analyzer: Quantitative assessment of risk events in the construction industry using fuzzy fault-tree analysis," J. Constr. Eng. Manag., vol. 137, no. 4, pp. 294-302, 2010.

[35] D. F. Gillespie, K. J. Robards, and S. Cho, "Designing safe systems: Using system dynamics to understand complexity," Nat. Hazards Rev., vol. 5, no. 2, pp. 82-88, 2004.

[36] F. Nasirzadeh, A. Afshar, M. Khanzadi, and S. Howick, "Integrating system dynamics and fuzzy logic modelling for construction risk management," Constr. Manag. Econ., vol. 26, no. 11, pp. 1197-1212, 2008.

[37] H. H. Choi, H. N. Cho, and J. W. Seo, "Risk assessment methodology for underground construction projects," J. Constr. Eng. Manag., vol. 130, no. 2, pp. 258-272, 2004.

[38] S. AbouRizk, P. Knowles, and U. R. Hermann, "Estimating labor production rates for industrial construction activities," J. Constr. Eng. Manag., vol. 127, no. 6, pp. 502-511, 2001.

[39] S. Mohamed, "Safety climate in construction site environments," J. Constr. Eng. Manag., vol. 128, no. 5, pp. 375384, 2002.

[40] R. K. McCann, B. G. Marcot, and R. Ellis, "Bayesian belief networks: Applications in ecology and natural resource management," Can. J. For. Res., vol. 36, no. 12, pp. 3053-3062, 2006.

[41] F. Y. Y. Ling, S. L. Chan, E. Chong, and L. P. Ee, "Predicting performance of design-build and design-bid-build projects," J. Constr. Eng. Manag., vol. 130, no. 1, pp. 75-83, 2004. 